\begin{tabular}{|c|c|}
\hline 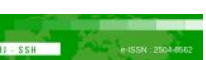 & Malaysian Journal of Social Sciences and Humanities (MJSSH) \\
\hline Malaysian Journal of & Volume 5, Issue 11, November 2020 \\
\hline (MJ-SSH) & e-ISSN : 2504-8562 \\
\hline & $\begin{array}{l}\text { Journal home page: } \\
\text { www.msocialsciences.com }\end{array}$ \\
\hline
\end{tabular}

\title{
Sorotan Literatur Bersistematik: Faktor Stres dalam kalangan Guru Matematik
}

\author{
Nur Izzati binti Ahmad Fuad', Siti Mistima Maat1 \\ ${ }^{1}$ Fakulti Pendidikan, Universiti Kebangsaan Malaysia (UKM) \\ Correspondence: Nur Izzati binti Ahmad Fuad (izzati.if@gmail.com)
}

\begin{abstract}
Abstrak
Stres dalam kalangan guru merupakan satu isu yang tidak boleh dipandang ringan. Amat penting bagi kita untuk memahami punca stres yang berlaku dalam kalangan guru kerana murid-murid akan menerima kesan secara terus daripada masalah kesihatan mental guru. Justeru kajian ini bertujuan untuk membuat tinjauan literatur bersistematik terhadap faktor-faktor yang mempengaruhi tahap stres guru khususnya guru matematik di sekolah. Dua persoalan kajian yang menjadi fokus utama ialah faktor-faktor stres dalam kalangan guru matematik serta metodologi kajian yang dijalankan dalam kajian-kajian lepas. Kajian ini menggunakan Model Prisma. Dua enjin carian digunakan iaitu Ebscohost dan Science Direct dan selepas proses saringan dilakukan sebanyak 18 buah artikel telah diterima berdasarkan beberapa kriteria yang ditetapkan. Dapatan menunjukkan terdapat 13 faktor yang menyebabkan stres dalam kalangan guru matematik dan kebanyakannya berpunca daripada persekitaran tempat kerja. Dari segi metodologi pula, bilangan kajian kuantitatif yang dijalankan adalah lebih banyak berbanding kajian kualitatif. Kesimpulannya, walaupun banyak faktor yang disenaraikan dalam kajian-kajian yang lepas, namun begitu jumlah kajian yang menekankan tentang kesihatan mental guru khususnya guru matematik masih belum begitu banyak. Justeru diharapkan agar kajian dalam bidang ini boleh diperbanyakkan lagi dalam konteks tempatan pada masa akan datang.
\end{abstract}

Kata kunci: faktor stres, guru matematik, kesihatan mental

\section{Systematic Literature Review Factors Affecting Stress Among Mathematics Teachers}

\begin{abstract}
Stress among teachers is an issue that should not be taken lightly. It is very important for us to understand the cause of stress that happens among teachers since the pupils will be directly affected by the teacher's mental health issues. Therefore, the purpose of this study is to make a systematic literature review towards the factors that is affecting teachers' stress level especially Mathematics teachers. Two main questions in this research are factors affecting stress level among mathematics teachers and method used in previous researches. This research use Model PRISMA. Two search engines were used; Ebscohost and Science Direct and after screening process 18 articles are accepted based on several criteria. Result shows there are 13 factors that cause stress among mathematics teachers and most of them comes from the workplace environment. In terms of methodology, the numbers of quantitative research that had been carry out is much more compare to qualitative research. In conclusion, even though there are many factors that had been listed in previous research, the number of research that emphasize on teachers'
\end{abstract}


mental health especially mathematics teachers is not that much. Therefore, hopefully more research will be conducted in local context in the future.

Keywords: stress factors, mathematics teacher, mental health

\section{Pengenalan}

Golongan dewasa merupakan yang paling ramai mengalami masalah stress berikutan komitmen dan tanggungjawab yang tinggi terutamanya di tempat kerja (Mohd Zawawi, Md. Sham \& Ismail. 2019). Tidak kira apa jua bidang pekerjaan pasti ada tekanan di tempat kerja. Seramai 2, 123 orang guru di Malaysia dilaporkan menghadapi stres tahap sederhana pada tahun 2018. Data diambil daripada seramai 48,258 orang responden.

Profesion perguruan merupakan antara bidang kerjaya berisiko tinggi disebabkan kesan yang tinggi pekerjaan tersebut ke atas kesihatan guru (Guglielmi \& Tatrow, 1998). Guru perlu berhadapan dengan pelbagai faktor yang menyumbang kepada stres seperti bebanan tugas, kesamaran peranan di tempat kerja, kurang sokongan sosial serta masalah pengurusan bilik darjah (M.Alarcon, 2011). Oleh sebab itu, individu yang terlibat dalam profesion perguruan cenderung untuk mengalami stres dan masalah kesihatan mental (Johnson et al., 2005).

Secara umumnya gejala stres terbahagi kepada tiga kumpulan iaitu gejala fizikal, perubahan emosi dan perubahan tingkah laku (Salleh, 2010). Antara gejala yang biasa berlaku apabila menghadapi stres ialah sakit kepala, mual, otot tegang, mudah meradang, pelupa, susah hati, menjadi pemarah, pengambilan alkohol dan rokok berlebihan, serta kurang daya tumpuan. Guru yang mengalami stres pada tahap yang tinggi cenderung untuk melakukan tingkah laku ganas terhadap murid (Hecker et al., 2018). Masalah ini memberi kesan terhadap keselamatan murid serta perkembangan emosi dan fizikal mereka.

Kajian ini bertujuan untuk mengkaji faktor berlakunya stres dalam kalangan guru matematik melalui tinjauan terhadap kajian-kajian empirikal berkaitan dengan stres dalam kalangan guru khususnya bidang matematik. Persoalan kajian adalah seperti berikut:

i. Apakah faktor berlakunya stres dalam kalangan guru matematik?

ii. Apakah pendekatan kajian yang dijalankan?

\section{Sorotan Literatur}

Stres merujuk kepada tekanan psikologi atau hubungan antara individu dengan persekitaran (Richard S. Lazarus, 1990). Stres berlaku apabila persekitaran menuntut sesuatu di luar kemampuan individu. Stres juga ditakrifkan sebagai perubahan yang berlaku ke atas seseorang individu sama ada dari segi fizikal atau mental yang disebabkan oleh paksaan atau tekanan (Zawawi et al., 2019).

Antara teori yang menjelaskan tentang stres ialah teori sindrom adaptasi am atau General Syndrom Adaptation (GAS). Terdapat tiga tahap dalam teori GAS ini iaitu tahap renjatan, tahap penahanan dan tahap kelesuan (Hussin et al., 2005). Dalam tahap renjatan, individu yang mengalami stres akan mengalami renjatan seperti jantung berdegup laju dan sakit tengkuk. Sekiranya individu berjaya melawan stres yang dihadapi dalam tahap renjatan, individu akan cuba menyesuaikan diri dengan stres pada tahap penahanan. Pada tahap kelesuan, sekiranya individu tidak lagi dapat mengawal stres, sistem pertahanan badan akan mula luput dan boleh menyebabkan kematian.

Richard Lazarus juga mengemukakan sebuah model yang menerangkan cara manusia bertindak apabila menerima rangsangan yang boleh mencetuskan stres. Model ini dijelaskan oleh Salleh (2010), iaitu stres hanya terbentuk apabila wujudnya punca stres yang boleh mendatangkan bahaya atau ancaman terhadap seseorang. Lazarus mencadangkan bahawa terdapat tiga peringkat penilaian rangsangan yang mungkin 
mencetuskan stres iaitu penilaian primer, penilaian sekunder dan penilaian semula kognitif. Penilaian primer ialah peringkat pertama yang menentukan sama ada rangsangan tersebut suatu ancaman. Penilaian sekunder ialah peringkat kedua yang menentukan sama ada seseorang itu dapat mengawal ancaman tersebut. Peringkat penilaian semula kognitif ialah peringkat ketiga iaitu melibatkan penilaian kognitif berdasarkan maklumat pada peringkat pertama dan kedua yang akan menentukan sama ada terjadinya stres atau tidak.

\section{Metod Kajian}

Sorotoan literatur bersistematik ini menggunakan garis panduan PRISMA seperti yang ditunjukkan dalam Rajah 1. Model PRISMA memberi panduan kepada penulis untuk membuat sorotan literatur bersistematik berasaskan bukti-bukti yang dikumpulkan oleh penulis. Nilai sorotan literatur bersistematik ini bergantung kepada pelaksanaan ulasan, dapatan kajian dan laporan yang jelas. Terdapat empat peringkat dalam menghasilkan sorotan literatur bersistematik iaitu mengenal pasti, menyaring, memeriksa kelayakan, dan merangkum.

\section{Rajah 1: Model PRISMA}

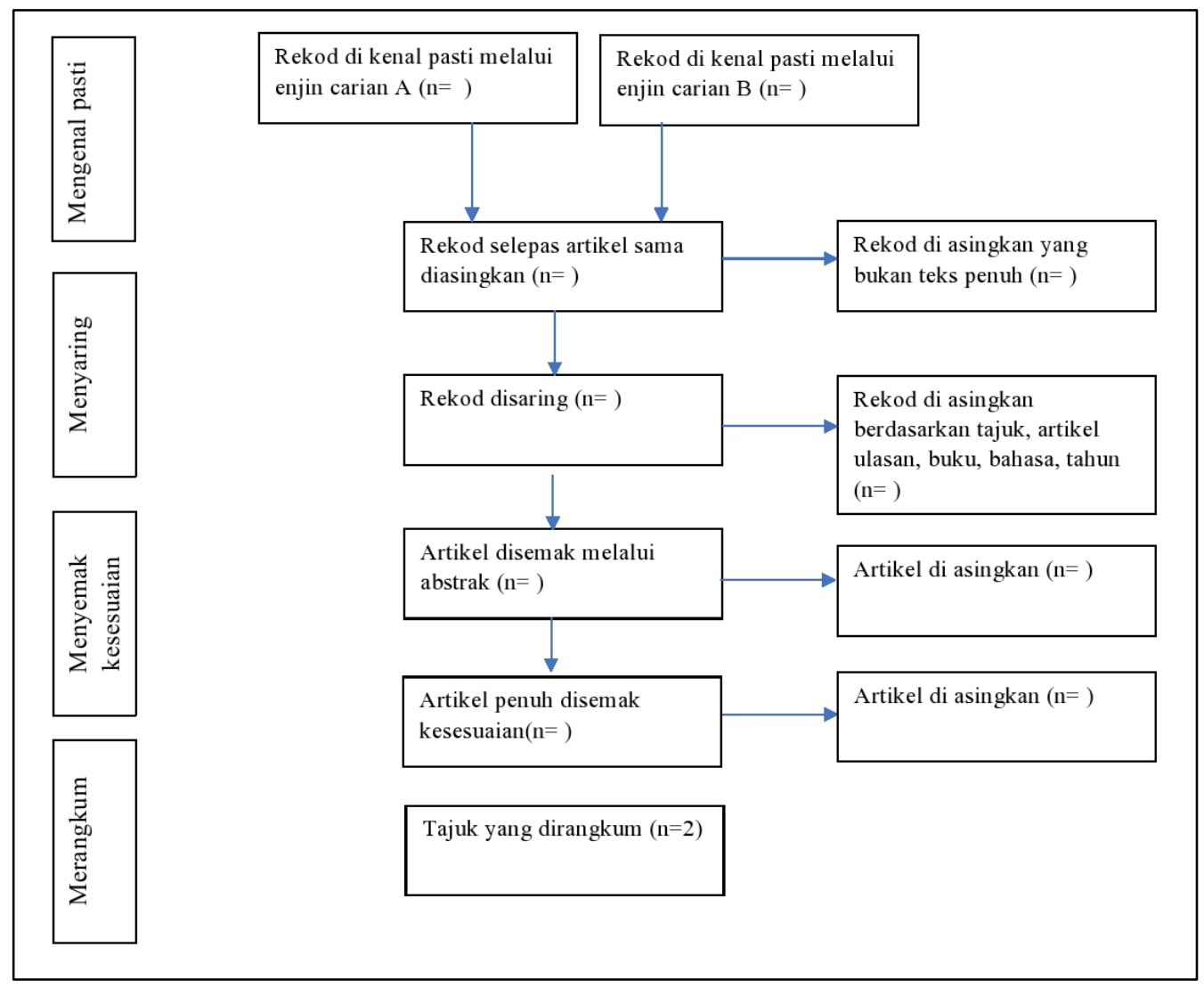

Dengan menggunakan enjin carian Ebscohost dan Science Direct, rekod kajian berkaitan stres dalam kalangan guru dikenal pasti. Artikel yang sama dalam kedua-dua enjin carian diasingkan. Setelah itu, rekod akan disaring berdasarkan kriteria yang diterima dan kriteria yang ditolak. Artikel perlulah relevan dengan kajian yang hendak dijalankan serta memberi nilai kepada kajian (Bavdekar, 2016) Justeru beberapa kriteria telah ditetapkan bagi memastikan artikel yang dipilih bersesuaian dengan kajian. Kriteria yang diterima ialah artikel mestilah dalam tempoh lima tahun terkini iaitu dari tahun 2016 hingga tahun 2020. Artikel yang dipilih mestilah melibatkan guru matematik sekolah rendah dan sekolah menengah atau di peringkat pengajian tinggi. Artikel mestilah kajian empirikal yang berbahasa Inggeris atau Bahasa Melayu sahaja agar mudah difahami isi kandungannya. Bagi kriteria yang ditolak ialah sebarang artikel sebelum tahun 2016, artikel yang bukan kajian empirikal seperti ulasan, buku, atau prosiding. Kajian selain dalam Bahasa Inggeris dan Bahasa Melayu juga dikecualikan. Kata kunci yang digunakan ialah "Stress among mathematics teachers". 
DOI: https://doi.org/10.47405/mjssh.v5i11.554

Jadual 1: Kriteria pemilihan artikel

\begin{tabular}{lll}
\hline Kriteria & Diterima & Ditolak \\
Tahun & 2016-2020 & $<2016$ \\
Bahasa & Bahasa Inggeris & Selain Bahasa Inggeris \\
Sumber & Artikel (kajian empirikal) & $\begin{array}{l}\text { Prosiding, buku, ulasan } \\
\text { artikel }\end{array}$ \\
\hline
\end{tabular}

Daripada 234 artikel yang telah disaring, 18 artikel telah dipilih berdasarkan kriteria yang diterima. Artikel yang ditolak adalah berikutan kajian tidak melibatkan guru matematik dan tidak melibatkan bidang perguruan

\section{Hasil Kajian}

Dapatan kajian menunjukkan terdapat 13 faktor yang menyebabkan stres dalam kalangan guru matematik. Terdapat lima kajian yang menunjukkan pengurusan bilik darjah menjadi punca stres bagi guru matematik manakala lima kajian lagi menyatakan bahawa persekitaran tempat kerja merupakan punca berlakunya masalah ini. Faktor seperti pengetahuan isi kandungan, jantina, beban kerja dan sikap murid pula masing-masing dinyatakan dalam dua kajian berbeza. Jangkaan guru, pengalaman guru, efikasi kendiri, serta anzieti juga antara faktor lain yang mengganggu kesihatan mental guru.

Jadual 2: Faktor stres dalam kalangan guru matematik

\begin{tabular}{ll}
\hline \multicolumn{1}{c}{ Penulis } & \multicolumn{1}{c}{ Faktor } \\
\hline $\begin{array}{l}\text { Keskin et al. (2018), D. Pedersen et al. } \\
\text { (2017), Narayan (2016), Bowen et al. (2017), }\end{array}$ & Pengurusan bilik darjah \\
$\begin{array}{l}\text { Paradis et al. (2018) } \\
\text { Keskin et al. (2018), Wu et al. (2017) }\end{array}$ & $\begin{array}{l}\text { Pengetahuan isi kandungan } \\
\text { Keskin et al. (2018) } \\
\text { Pedersen et al. (2017), D. Pedersen et al. }\end{array}$ \\
$\begin{array}{l}\text { Jangkaan guru } \\
\text { (2017) }\end{array}$ & Beban kerja \\
Cui et al. (2018), Narayan (2016) & Pengalaman \\
Thibaut (2018) & Perkembangan profesional \\
Thibaut (2018) & Anzieti \\
Stoehr (2017) & Pencapaian murid \\
Alrajhi et al. (2017) & Efikasi kendiri \\
Perera et al. (2020) & Sikap murid \\
Perera et al. (2020), Martínez-sierra et al. & \\
(2019 & Penggunaan ICT \\
Tanas et al. (2020) & Persekitaran tempat kerja \\
Zakariya (2020), Banerjee et al. (2017), & \\
Narayan (2016), Turner et al. (2019), Al et al. \\
(2017)
\end{tabular}

\section{Pengurusan bilikdarjah}

Pengurusan bilik darjah merupakan salah satu faktor yang menyumbang kepada berlakunya stres dalam kalangan guru matematik. Guru yang mempunyai kawalan kelas yang baik kurang tertekan berbanding guru yang lemah kawalan kelasnya (Bowen et al. 2017; Narayan 2016; Paradis et al. 2018). Guru wanita pula mempunyai masalah dalam mengawal kelas berbanding dengan guru lelaki (D. Pedersen \& West, 2017). 


\section{Persekitaran tempatkerja}

Persekitaran tempat kerja yang positif boleh mengurangkan tekanan di tempat kerja. Sokongan sosial daripada rakan sekerja juga menjadikan persekitaran di sekolah lebih baik (Banerjee et al., 2017; Narayan, 2016; Zakariya, 2020). Persekitaran tempat kerja juga mempunyai hubungan yang signifikan dengan tahap kepuasan bekerja. Kemudahan ruang kerja guru yang sempit antara punca guru mudah tertekan di tempat kerja.

\section{Pengetahuan isi kandungan}

Amat penting bagi guru matematik menguasai pengetahuan isi kandungan dalam mata pelajaran tersebut. Penguasaan pengetahuan isi kandungan membantu guru menyampaikan pelajaran dengan baik. Sekiranya guru belum menguasai bahagian ini, kemungkinan guru akan menghadapi kesukaran untuk menyampaikan pdp dan mudah berasa tertekan (Keskin et al., 2018; Wu et al., 2017).

\section{Sikap murid}

Oleh sebab guru sentiasa berinteraksi secara langsung dengan murid, kemungkinan sikap murid menjadi punca stres kepada guru-guru memang tinggi. Sikap murid yang merunsingkan termasuklah masalah disiplin dalam bilik darjah serta kurang penglibatan ketika mata pelajaran matematik (Martínez-sierra \& Hernández-moreno, 2019).

\section{Jantina}

Di sekolah layanan yang diterima oleh guru wanita dan guru lelaki berbeza. Gaji tahunan yang diterima oleh guru wanita adalah lebih sedikit berbanding guru lelaki. Dari segi hubungan dengan pentadbir, layanan yang diberikan terhadap guru lelaki adalah lebih baik berbanding guru wanita. Guru wanita juga seringkali tidak menerima maklumat yang penting dalam sekolah berbanding guru lelaki (D. Pedersen \& West, 2017).

\section{Beban kerja}

Beban kerja guru masa kini tidak dapat dinafikan berbeza dengan masa dahulu. Jumlah waktu bertugas guru adalah lebih panjang tidak termasuk tugas sampingan di hujung minggu (Narayan, 2016). Kerjakerja dokumentasi yang perlu diselesaikan juga semakin bertambah. Di samping itu, perkakasan keperluan guru untuk mengajar juga perlu disediakan sendiri.

\section{Lain-lain}

Faktor-faktor lain yang menyumbang kepada peningkatan tahap stres guru adalah seperti kebimbangan dalam matematik, kurang pengalaman, meletakkan jangkaan yang tinggi dalam pdp, efikasi kendiri guru, pencapaian murid serta penggunaan ICT dalam PDP.

Dapatan kajian bagi persoalan kedua adalah seperti jadual 3 berikut:

Jadual 3: Kaedah kajian

\begin{tabular}{lc}
\hline Penulis & Kaedah kajian \\
\hline D. Pedersen et al.(2017), D. E. Pedersen et al. & Kuantitatif \\
(2017), Cui et al. (2018), Thibaut (2018), & $(\mathrm{n}=12)$ \\
Alrajhi et al. (2017), Perera et al. (2020), & \\
Tanas et al. (2020), Zakariya (2020), Banerjee & \\
et al. (2017), Narayan (2016), Bowen et al.( & \\
2017), Al et al. (2017) & \\
\hline
\end{tabular}




\begin{tabular}{lc}
\hline Keskin et al.( 2018), Wu et al. (2017), Stoehr & Kualitatif \\
$(\mathrm{n}=6)$ & \\
et al.(2018), Martínez-sierra et al. (2019), Paradis & \\
\hline
\end{tabular}

Berdasarkan jadual, sebanyak 12 buah kajian dijalankan menggunakan kaedah kuantitatif manakala 6 kajian lagi menggunakan kaedah kualitatif. Kaedah kuantitatif melibatkan jumlah peserta kajian yang lebih ramai dan membantu pengkaji membuat generalisasi ke atas sesuatu populasi atau melihat trend dalam sesuatu kumpulan. Kaedah kualitatif pula membantu pengkaji mendapatkan maklumat yang mendalam mengenai sesuatu fenomena.

\section{Perbincangan Kajian}

Berdasarkan hasil kajian, faktor-faktor yang menyumbang kepada stres dalam kalangan guru matematik adalah berkaitan dengan isu yang sering timbul di tempat kerja. Masalah seperti pengurusan bilik darjah, beban kerja, sikap murid serta kurang penguasaan isi kandungan menjadi punca berlakunya stres. Tahap kesihatan mental guru perlu diambil berat memandangkan mereka berhadapan dengan cabaran yang besar dalam menyampaikan ilmu lebih-lebih lagi di era serba canggih ini. Sokongan yang berterusan daripada pihak pentadbir serta masyarakat mampu mengurangkan tekanan yang dihadapi oleh para guru.

Di Malaysia, KPM mengambil serius akan masalah ini dan meminta pihak sekolah menyediakan kawasan rehat guru bagi memberi ruang yang selesa untuk guru bertenang memandangkan kemudahan bilik guru yang ada di kebanyakan sekolah adalah kurang baik. Selain itu, KPM juga telah menganjurkan kursus kesedaran kesihatan mental kepada guru-guru di Malaysia agar guru-guru sedar akan tahap kesihatan mental mereka. Jabatan pendidikan di setiap negeri pula menyediakan khidmat kaunseling kepada mana-mana guru yang memerlukan bantuan. Usaha murni seperti ini harus digiatkan lagi agar masalah stres dalam kalangan guru dapat dikurangkan.

\section{Kesimpulan}

Ulasan literatur bersistematik ini sedikit sebanyak membantu memberi pencerahan tentang faktor-faktor berlakunya stres dalam kalangan guru matematik. Tidak banyak kajian yang memfokuskan kepada masalah kesihatan mental khususnya dalam kalangan guru matematik. Walau bagaimanapun, maklumat yang diperoleh daripada kajian pelbagai negara memberi input yang bermakna dalam kajian ini.

\section{Rujukan}

Al, M. K., Carole, S., \& Michael, J. M. (2017). Assessing changes in teachers' attitudes toward. Int J Technol Des Educ, 63-88. https://doi.org/10.1007/s10798-015-9341-0

Alrajhi, M., Aldhafri, S., Alkharusi, H., \& Albusaidi, S. (2017). The predictive effects of math teachers ' emotional intelligence on their perceived self-ef fi cacy beliefs. Teaching and Teacher Education, 67, 378-388. https://doi.org/10.1016/j.tate.2017.07.003

Banerjee, N., Stearns, E., Moller, S., \& Mickelson, R. A. (2017). Teacher Job Satisfaction and Student Achievement: The Roles of Teacher Professional Community and Teacher Collaboration in Schools. American Journal of Education, 123(FEBRUARY).

Bavdekar, S. B. (2016). Enhance the value of a research paper: Choosing the right references and writing them accurately. Journal of Association of Physicians of India, 64(MARCH), 66-70.

Bowen, B., Marx, A., Williams, T., \& Napoleon, L. (2017). School Influence and Classroom Control: A Comparison of Career and Technical Education, Science, and Mathematics Teachers. Career and Technical Education Research, 42(3). https://doi.org/10.5328/cter42.3.183

Castillo-Gualda, R., Herrero, M., Rodríguez-Carvajal, R., Brackett, M. A., \& Fernández-Berrocal, P. (2019). The role of emotional regulation ability, personality, and burnout among spanish teachers. International Journal of Stress Management. https://doi.org/10.1037/str0000098 
Cui, Q., Chao, Q., Han, J., Zhang, X., Ren, Y., \& Shi, J. (2018). Job stress, burnout and the relationship among the science and mathematics teachers in basic education schools. Eurasia Journal of Mathematics, Science and Technology Education, 14(7), 3235-3244. https://doi.org/10.29333/ejmste/85957

Guglielmi, R. S., \& Tatrow, K. (1998). Occupational Stress, Burnout, and Health in Teachers: A Methodological and Theoretical Analysis. Review of Educational Research, 1(68), 61-99.

Hecker, T., Goessmann, K., Nkuba, M., \& Hermenau, K. (2018). Teachers' stress intensifies violent disciplining in Tanzanian secondary schools. Child Abuse \& Neglect, 76, 173-183.

Hussin, S., Marzuki, S. @ C., Razak, A. Z. A., Som, H. M., \& Ranee, A. (2005). Pentadbiran dalam Pembangunan Pendidikan (S. Hussin, S. Marzuki, A. Z. A. Razak, H. M. Som, \& A. Ranee (eds.)). PTS Professional Publishing Sdn Bhd.

Johnson, S., Cooper, C., Cartwright, S., Donald, I., Taylor, P., \& Millet, C. (2005). The experience of work-related stress across occupations. Journal of Managerial Psychology, 20(2), 178-187.

Keskin, Ö., Çorlu, M. S., \& Ayas, A. (2018). Voicing mathematics teachers: A holistic overview of their early career challenges. Kuram ve Uygulamada Egitim Bilimleri, 18(2), 331-371. https://doi.org/10.12738/estp.2018.2.0025

M.Alarcon, G. (2011). A meta-analysis of burnout with job demands, resources, and attitudes. Journal of Vocational Behaviour, 79(2), 549-562.

Martínez-sierra, G., \& Hernández-moreno, A. (2019). Daily Emotional Experiences of a High School Mathematics Teacher in the Classroom : a Qualitative Experience-Sampling Method. 591-611.

Narayan, N. A. (2016). Factors Influencing Teacher Career Satisfaction, Teacher Collaboration and Everyday Challenges : An Exploratory Factor Analysis. Malaysian Online Journal of Educational Sciences, 4(3), 24-38.

Paradis, A., Lutovac, S., Jokikokko, K., \& Kaasila, R. (2018). Canadian and Finnish upper-secondary school mathematics teachers ' perceptions of autonomy. Pedagogy, Culture \& SoCiety, 26(3), 381396.

Pedersen, D. E., \& Minnotte, K. L. (2017). Workplace Climate and STEM Faculty Women's Job Burnout. Journal of Feminist Family Therapy, 29(1-2), 45-65. https://doi.org/10.1080/08952833.2016.1230987

Pedersen, D., \& West, R. (2017). High School STEM Teachers' Perceptions of the Work Environment. Education, 138(1).

Perera, H. N., \& John, J. E. (2020). Teacher's self-efficacy beliefs for teaching maths: Relations with teacher and students outcome. Contemporary Educational Psychology, 61.

Richard S. Lazarus. (1990). Theory-Based Stress Measurement. Psychological Inquiry, 1(1), 3-13. https://doi.org/: 10.1207/s15327965pli0101_1

Salleh, M. R. (2010). Pengendalian Stres dan Kebimbangan: Penilaian kognitif dan tingkah laku. Universiti Sains Malaysia.

Stoehr, K. J. (2017). Building the wall brick by brick : one prospective teacher' s experiences with mathematics anxiety. J Math Teacher Educ, 119-139. https://doi.org/10.1007/s10857-015-9322-y

Tanas, L., Winkowska-Nowak, K., \& Pobiega, K. (2020). The Importance of Teachers' Need for Cognition in Their Use of Technology in Mathematics Instruction. Frontiers in Psychology, 11(February), 1-11. https://doi.org/10.3389/fpsyg.2020.00259

Thibaut, L. (2018). How school context and personal factors relate to teachers' attitudes towards teaching integrated STEM. Int J Technol Des Educ, 631-651.

Turner, K., \& Theilking, M. (2019). Teacher wellbeing: Its effects on teaching practice and student learning. Issues in Educational Research, 29(3), 938-961.

Wu, Y., Hwang, S., \& Cai, J. (2017). Being a Mathematics Teacher Educatorin China : Challenges and Strategic Responses. 1365-1384. https://doi.org/10.1007/s10763-016-9752-8

Zakariya, Y. F. (2020). Effects of school climate and teacher self- efficacy on job satisfaction of mostly STEM teachers: a structural multigroup invariance approach. International Journal of STEM Education, 4.

Zawawi, N. I. M., Md Sham, F., \& Ismail, A. (2019). Stress according to the western and Muslim scholars. International Journal of Islamic Thought, 16, 85-97. https://doi.org/10.24035/ijit.16.2019.008 